\title{
Representações sociais de paternidade na revista Pais \& Filhos (1969-2008)
}

\section{Social representations of fatherhood in Pais \& filhos magazine (1969-2008)}

\footnotetext{
${ }^{[a]}$ Doutor em Psicologia pela Universidade Federal do Espírito Santo (Ufes), professor do Departamento de Psicologia e Programa de Pós-Graduação em Psicologia da Universidade Federal de Minas Gerais (UFMG), Belo Horizonte, MG - Brasil, e-mail: nascimento@fafich.ufmg.br

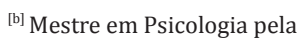
Universidade Federal de Minas Gerais (UFMG), Belo Horizonte, MG - Brasil, e-mail: gabriela.tvieira@pbh.gov.br

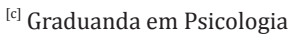
pela Universidade Federal de Minas Gerais (UFMG), Belo Horizonte, MG - Brasil, e-mail: anacarolinaroriz@hotmail.com

${ }^{\text {[d] }}$ Graduanda em Psicologia pela Universidade Federal de Minas Gerais (UFMG), Belo Horizonte, MG - Brasil, e-mail: michellemarielouised@yahoo. com.br

${ }^{[\mathrm{e}]}$ Graduanda em Psicologia pela Universidade Federal de Minas Gerais (UFMG), Belo Horizonte, MG - Brasil, e-mail: monica_ipa@hotmail.com

${ }^{\text {[f] }}$ Graduanda em Psicologia pela Universidade Federal de Minas Gerais (UFMG), Belo Horizonte, MG - Brasil, e-mail: raquelalves03@gmail.com
}

Recebido: 03/12/2010 Received: $12 / 03 / 2010$

Aprovado: $10 / 03 / 2011$ Approved: 03/10/2011

\author{
Adriano Roberto Afonso do Nascimento ${ }^{[a]}$, Gabriela T. Vieira ${ }^{[b]}$, Ana Carolina R. Mesquita ${ }^{[c]}$, \\ Michelle M. L. O. Gomes ${ }^{[d]}$, Monica C. Silva ${ }^{[e]}$, Raquel G. S. Alves ${ }^{[]]}$
}

\begin{abstract}
Resumo
O objetivo dessa investigação foi identificar e analisar as representações sociais de paternidade veiculadas pela revista Pais \& Filhos entre 1969 e 2008. Foram selecionados, para a análise, 40 exemplares dessa revista (um exemplar por ano; seleção aleatória do mês). Desse conjunto, foram transcritos todos os 190 itens (reportagens, entrevistas, colunas de especialistas, anúncios publicitários) que apresentavam os vocábulos "pais", "pai", "paternidade", "paternal" e variantes. 0 corpus formado foi submetido à análise lexical realizada pelo software ALCESTE. Foram identificadas as seguintes classes de formas reduzidas: "nós, as crianças e nossas histórias", "relacionando-se com crianças e adolescentes", “terapia”, "as doenças dos bebês" e "pai jurídico". Em seu conjunto, os resultados indicam que, no corpus analisado, a representação social de paternidade é composta por elementos que concedem ao pai o lugar de coadjuvante ou, mais recorrentemente, o identificam como uma referência problemática (causador de problemas ou como eventual possibilidade de solução).
\end{abstract}

Palavras-chave: Paternidade. Representações sociais. Mídia.

\begin{abstract}
This research aimed to identify and analyze the social representations of fatherhood conveyed by the Pais \& Filhos magazine from 1969 to 2008. Forty issues of the magazine were selected for analysis (one piece per year, at random selection of the month). From this group, all 190 items (reports, interviews, expert columns and advertisements) that showed the words "parents", "father", "paternity", "parental" and variants were transcribed. The corpus formed was subjected to lexical analysis in the software ALCESTE. We identified the following classes of reduced form: "we, the children and our stories," "interacting with children and adolescents", "therapy", "babies' diseases" and "legal father". Taken together, these results indicate that in the corpus examined, the social representation of fatherhood is made of elements that give the father the supporting role, or more frequently, identify the father as a problematic reference (troublemaker or as an eventual possibility of solution).
\end{abstract}

Keywords: Fatherhood. Social representations. Media. 


\section{Introdução}

Vem recebendo destaque crescente nos meios de comunicação a emergência/consolidação do que se tem denominado "novo pai". Tal destaque, que tem como base a percepção mais geral sobre as mudanças nas expectativas de papel relacionadas à criação de filhos nas últimas décadas, é acompanhado por uma tendência de aumento também nos estudos acadêmicos sobre a paternidade.

Se, pelo menos até o fim da década de 90 , parte dessa produção, como afirmam Trindade (1998) e Fonseca (1998), pouco se preocupou em ouvir efetivamente os pais, privilegiando a percepção feminina sobre a paternidade, mais recentemente identifica-se um maior investimento em estudos que procuram compreender as vivências e expectativas dos homens em relação à condição paterna.

No conjunto desses estudos mais recentes, destaca-se a grande variedade de grupos sociais abordados e de temas associados, entre os quais encontramos, por exemplo: preocupações e medos dos pais relacionados à saúde da mãe e do bebê durante a gravidez (Krob, Piccinini \& Silva, 2009; Piccinini, Levandowski, Gomes, Lopes \& Lindenmeyer, 2009), paternidade na adolescência (Dias \& Aquino, 2006; Hoga \& Reberte, 2009), participação masculina nos cuidados infantis (Silva \& Piccinini, 2007; Sutter \& Bucher-Maluschke, 2008), assistência ao parto (Carvalho \& Brito, 2008), concepções, vivências e comportamentos relacionados ao aleitamento materno (Pontes, Alexandrino \& Osorio, 2009), paternidade social (Costa \& Rossetti-Ferreira, 2007; Ghirardi, 2009) e infertilidade (Borlot \& Trindade, 2004).

Também parte desse conjunto mais recente de estudos, encontramos aqueles que se referem ao papel da mídia na veiculação e construção de referências sobre a paternidade. Nesse sentido, alguns autores indicam, por exemplo, como a mídia vem reiterando o caráter ideal da díade paternidade/maternidade (Chechi \& Hillesheim, 2008; Hennigen \& Guareschi, 2008; Rodrigues, 2000; Santos, 2005), muitas vezes baseada no discurso de especialistas (Hennigen, 2010; Santos, 2005). Se é verdade que alguns veículos de comunicação têm enfatizado mudanças na atuação paterna, considerado-a atualmente como mais participativa, mantém-se, por vezes, a prescrição de modelos que desconsideram a diversidade de aspectos relevantes que matizam esses mesmos modelos nas vivências cotidianas dos pais (Chechi \& Hillesheim, 2008).

Contudo, ainda que veiculem modelos aparentemente simplistas, os meios de comunicação são considerados tradicionalmente uma fonte promissora para o estudo de objetos que possuem reconhecida relevância social durante um maior período de tempo. Especificamente os periódicos (de circulação mais abrangente a partir das primeiras décadas do século XX) que se propõem à abordagem de um grupo específico de temas/ objetos sociais são especialmente interessantes como instrumentos para acompanhar as mudanças ocorridas nos discursos sobre esses temas/objetos (Martins, 2008; Buitoni, 2009). Reconhece-se atualmente que esses periódicos, mais do que se caracterizarem como veículos que refletem as concepções de seus editores e colaboradores, difundem ou propagam representações sociais de determinado objeto, construídas e reiteradas nas relações intergrupo, constituindo um conjunto mais amplamente difundido de percepções e prescrições sobre/para ações cotidianas dos sujeitos aos quais se relaciona diretamente esse objeto (Moscovici, 2004; Vidal, Rateau \& Moliner, 2006).

De acordo com a Teoria das Representações Sociais, "como sistemas de entendimento compartilhado do mundo, as representações oferecem padrões de conhecimento e reconhecimento, disposições, orientações e conduta, que transformam ambientes sociais em lares para atores individuais e lhes permite entender as regras do jogo" (Jovchelovitch, 2007, p. 191). Mais especificamente, as representações sociais podem ser entendidas como

uma forma de pensamento social, cuja gênese, propriedades e funções devem ser relacionadas com os processos que afetam a vida e a comunicação sociais, com os mecanismos que concorrem para a definição da identidade e a especificidade dos sujeitos sociais, indivíduos ou grupos, assim como a energética que está na origem das relações que esses grupos mantêm entre si (Jodelet, 2005, p. 50).

Considerando-se as informações apresentadas, o objetivo desta investigação foi acompanhar as manutenções e modificações das representações sociais de paternidade veiculadas por uma publicação já tradicional no mercado brasileiro, a revista Pais \& Filhos. 


\section{Revista Pais \& Filhos}

A revista Pais \& Filhos é a mais antiga revista do segmento em circulação no país; editada atualmente pela Manchete Editora, foi editada pela Bloch Editores entre 1968, ano de seu lançamento, e 2000. Embora na coluna "Nosso DNA" afirme-se que ela pretende ser hoje uma revista para a "família, para a grávida, o grávido e para os pais de crianças até 12 anos. Para quem engravida da forma tradicional, para aqueles que correm atrás do sonho com a ajuda da reprodução assistida e também para quem decide adotar" (2010, n. 485, p. 6), alguns estudos que a utilizaram como fonte indicam que são as mães o seu público-alvo (Assunção, 2010; Schwengber \& Meyer, 2007), mais especificamente, segundo Assunção (2010), as mães-esposas cuidadoras da família e do lar.

\section{Metodologia}

Foram selecionados 40 exemplares da revista Pais \& Filhos, publicados entre 1969 e 2008 (um exemplar por ano; seleção aleatória do mês). Desse conjunto, foram transcritos todos os 190 itens (reportagens, entrevistas, colunas de especialistas, anúncios publicitários) que apresentavam os vocábulos "pais" (a inclusão desse vocábulo é justificada, pois se presume que sua utilização pressupõe referência a mãe e a pai), "pai", "paternidade", "paternal" e variantes. 0 corpus formado por esses 190 itens foi submetido à análise lexical realizada pelo software ALCESTE (Analyse Lexicale par Context d'un Ensemble de Segments de Texte) ${ }^{1}$.

\section{Resultados}

A análise lexical realizada com o auxílio do software ALCESTE gerou, a partir das 4.291 unidades de contexto elementar $\left(\right.$ UCE) ${ }^{2}$ classificadas, cinco classes de formas reduzidas (Classificação Hierárquica Descendente, Formas reduzidas distribuídas por classe, Figura 1).

A Classe 1 (28,92\% das UCEs), denominada "Nós, as crianças e nossas histórias", identifica o agrupamento das formas "eu" $\left(X^{2}=222,76\right)$, "gent+" $\left(X^{2}=201,04\right)$, "ach+" $\left(X^{2}=102,81\right)$, "ano+" $\left(X^{2}=100,15\right)$ e "gost+" $\left(X^{2}=98,91\right)$ e aponta como variáveis características os períodos 1969-1973 e 2004-2008.

A essa primeira classe associam-se as Classes 2 ("Relacionando-se com crianças e adolescentes") e 4 ("Terapia"). A Classe 2 (31,97\% das UCEs) é composta pelas formas reduzidas "pais" $\left(X^{2}=233,86\right)$, "filhos" $\left(X^{2}=104,79\right)$, "adolescente+" $\left(X^{2}=98,41\right)$, "amor+" $\left(X^{2}=97,96\right)$ e "relact" $\left(X^{2}=93,65\right)$ e possui como variáveis características os períodos 1994-1998 e 1999-2003. Por sua vez, a Classe 4 (8,32\% das UCEs) é formada por "socit" $\left(X^{2}=335,05 \%\right)$, "familiar" $\left(X^{2}=192,45 \%\right)$, "terapeut+" $\left(X^{2}=169,39 \%\right)$ e "psiquiatr+" $\left(X^{2}=132,01 \%\right)$, tendo como variáveis características 1969-1973 e 1974-1978.

A Classe 3 ("As doenças dos bebês"; 22,44\% das UCEs), que se relaciona ao conjunto formado pelas Classes 1, 2 e 4, é formada por "beb+" $\left(X^{2}=503,60\right)$, "pediatr+" $\left(X^{2}=182,27\right)$, "fet+" $\left(X^{2}=160,69\right)$, "leite+" $\left(X^{2}=157,26\right)$ e "agu+" $\left(X^{2}=144,87\right)$ e possui os períodos 1979-1983, 1989-1993 e 2004-2008 como variáveis características.

"Pai jurídico" (Classe 5; 8,34\% das UCEs) nomeia o conjunto de formas reduzidas "registr+" $\left(X^{2}=873,33\right)$, lei $\left(X^{2}=453,95\right)$, "reconhecimento" $\left(X^{2}=407,41\right)$ e "alimentíc+" $\left(X^{2}=397,36\right)$ e apresenta como variáveis características os períodos 1974-1978 e 1984-1988.

Transcrevemos, deste ponto em diante, algumas das UCEs características das cinco classes ${ }^{3}$.

Os trechos apresentados para a Classe 1 (Nós, as crianças e nossas histórias) descrevem as atividades e brincadeiras infantis, com destaque para as histórias que reiteram a infância como um período de inocência e de descoberta:

\footnotetext{
1 O software ALCESTE identifica coocorrências de palavras em segmentos de textos, indicando, a partir da composição de classes de palavras fortemente associadas em um determinado discurso, elementos da organização geral (estruturação e significados) do tema-alvo desse mesmo discurso (Kalampalikis, 2003; Reinert, 1998, 2001; Nascimento \& Menandro, 2006).

2 As unidades de contexto elementar são segmentos dos textos submetidos à análise lexical.

3 Em negrito estão as palavras incluídas em cada uma das classes.
} 
... quem pede tudo isso a Papai Noel é Marcelo, que tem apenas três anos e meio. Já sua amiguinha Mariana, com quase cinco anos, quer só uma casinha de boneca e para ela o natal é uma coisa feliz que a gente sente ( $\left[X^{2}=39\right]$, Lúcia Etienni Romeu, 1975, "No Natal, o melhor brinquedo não substitui o amor", p. 8).

0 que é que tem? Claudia vira-se para a pirralha e diz: você, quando crescer, vai ter que ir pro colégio, entendeu? Pro colégio. ALEXANDRE: Alexandre, com três anos de transar e curtir infância gostosa, deu uma dentada na Marcela que veio se queixar à tia: olha só o que o Alexandre me fez! ( $\left[X^{2}=37\right]$, Pedro Bloch, 1973, “Criança diz cada uma”, p. 40).

As UCEs características da Classe 2, por sua vez, tratam do relacionamento com crianças e adolescentes. Podemos considerar, a partir desses fragmentos, que essa classe apresenta os aspectos nem sempre tranquilos da etapa de transição da infância para a adolescência, tanto para os pais quanto para os(as) filhos(as):

... mesmo pequenas, elas usam de artifícios como esse para atrair a atenção dos adultos sobre si. 0 importante é que os pais não supervalorizem esse momento nem fantasiem que os pequenos fazem isso para chateá-los, pois, com quanto mais naturalidade lidarem com essa fase de regressão e menos demonstrarem sua preocupação... ([ $\left.X^{2}=23\right\}$, Cláudia Werneck, 1991, "Chegou a hora de deixar as fraldas", p. 39).

... sem o marido, que estava trabalhando, e sem as crianças, surgia o sentimento de solidão. Hoje, muitas mulheres ainda possuem esse modelo antigo, e não conseguem descobrir a alegria de ser mães de adolescentes e adultos. ([ $\left.X^{2}=23\right]$, Andrea Boechat, 1995, "Mãe \& Filho — um amor diferente", p. 33).

É na adolescência que os jovens têm mais necessidade de se sentirem úteis, independentes, porque assim eles vão, aos poucos, se tornando amadurecidos e capazes de superar todas as crises da idade ( $\left[X^{2}=21\right]$, Sônia Machado, 1970, "Chegou o tempo de meu filho trabalhar", p. 42-45).

As UCEs características da Classe 4 referem-se à terapia, principalmente à terapia familiar, constituindo o primeiro agrupamento do discurso dos especialistas no corpus analisado. Como se observa na Figura 1, as Classes 2 e 4 possuem um forte vínculo.
Esse vínculo baseia-se na díade problema/solução. UCEs características da Classe 4:

... as terapias das relações familiares. Ainda que restrita a poucos círculos, a terapia familiar já possui hoje, no Brasil, um considerável número de adeptos e estudiosos. Com apenas 20 anos de existência em todo mundo, essa nova técnica terapêutica defende a participação da família no trabalho de tratamento de um de seus membros, encarando os problemas do paciente como sintomas de dificuldades de um todo, a família ( $\left[X^{2}=65\right]$, Jalusa Barcelos, 1977, "As terapias das relações familiares", p. 88-91).

... pois este, aliás, na opinião de Lindemberg Rocha, é o ponto nevrálgico de um trabalho terapêutico a nível familiar. A terapia da família não é uma orientação no sentido de mostrar como as pessoas devem agir, porque aí se estaria apenas utilizando o psicólogo com o intuito de ajustar a família a uma situação social, ou melhor, ao sistema social ([ $X^{2}=$ 57], Jalusa Barcelos, 1977, "As terapias das relações familiares", p. 88-91).

Trechos que fazem referências à saúde e às doenças dos bebês encontram-se agrupados na Classe 3 . Essa é uma classe na qual a referência técnica, o segundo discurso de especialistas, particularmente da medicina, é evidente:

... os estudiosos verificaram que a mesma proteína, por coincidência o nosso já conhecido antígeno D, também era encontrada no sangue humano. Mas de que forma as gestantes Rh negativo agridem o bebê Rh positivo? Durante a gravidez, as hemácias do sangue do feto contendo anti D entram na circulação materna através da placenta ou do cordão umbilical ( $\left[X^{2}=41\right]$, Letícia Belfort, 1992, "Rh. Perigo é coisa do passado", p. 37).

Além disso, o bebê tomara leite contaminado por nicotina. $O$ que pode causar cólica, sensibilização alérgica da via respiratória, tosse ou rinite, e irritabilidade, pois a substância atinge o sistema nervoso do bebê, que é muito imaturo ( $\left[X^{2}=39\right]$, Luis Clemente, 1994, “Você fuma e... seu filho também”, p. 30-32).

Finalmente, a Classe 5 reúne os trechos referentes ao terceiro discurso de especialistas. Trata-se do agrupamento de referências às situações que envolvem separação judicial, pensão, reconhecimento de paternidade e pensão. Como visto, demos a essa 


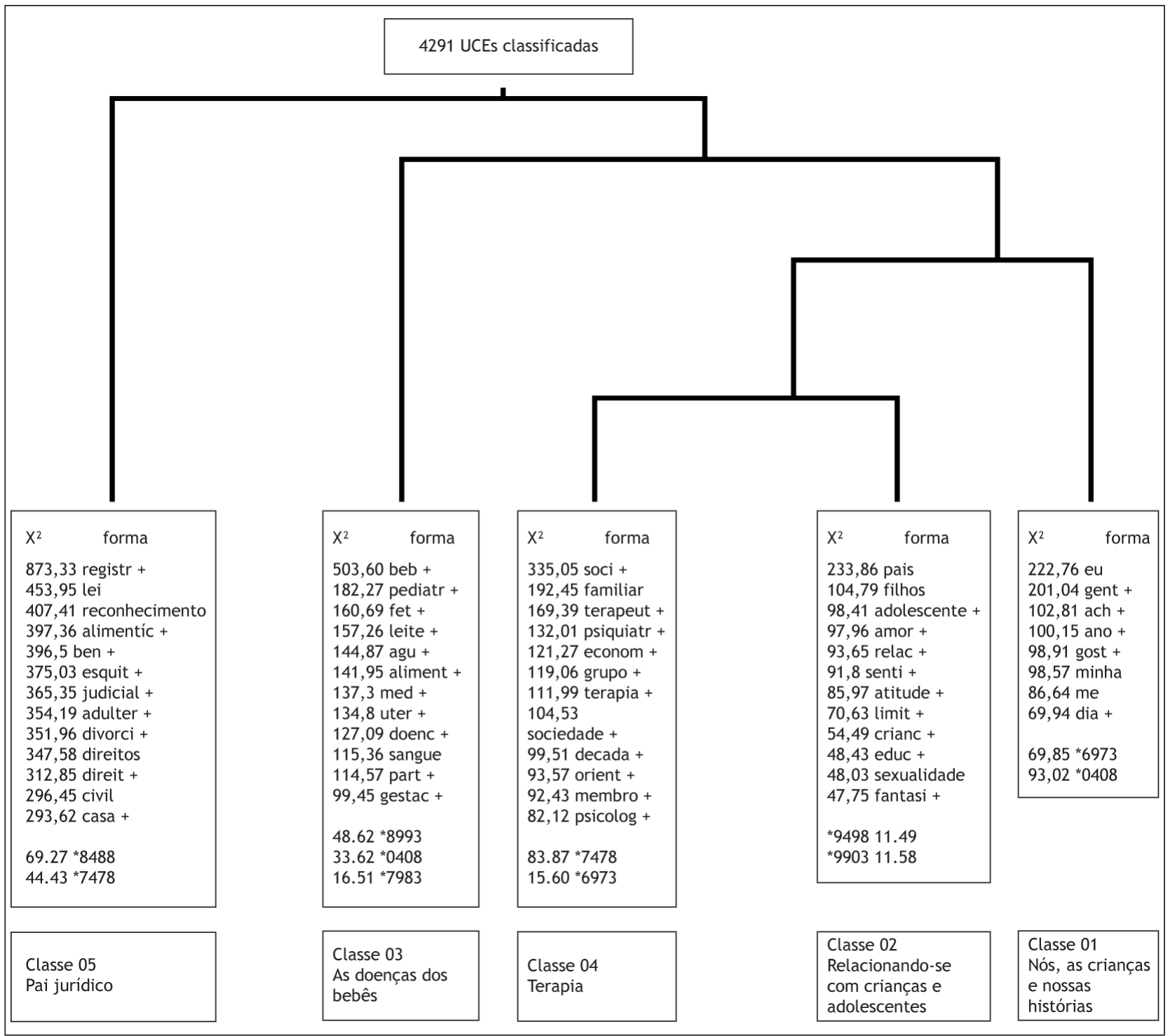

Figura 1- Formas reduzidas distribuídas por classe

Fonte: Dados da pesquisa.

classe o nome "Pai jurídico". A seguir, as UCEs características da Classe 5 :

... na ação de investigação de paternidade não se vai averbar o nome do pai no registro de nascimento, mas assegurar-se a prestação alimentícia. Posteriormente, com a morte do pai ou com a sua separação, será possível averbação. Filho não é obrigado a ter sobrenome do pai $\left(\left[X^{2}=114\right]\right.$, Haroldo Lins e Silva, 1984, "Você frente a frente com o advogado de família”, p. 91).

... com a presente resposta, o filho já nasceu. 0 registro poderá ser feito exclusivamente pela mãe, pois há proibição legal para o reconhecimento de filho adulterino. Nada impede que haja reivindicação de alimentos contra o pai, muito embora o seu nome não conste no seu registro de nascimento ([ $\left.X^{2}=100\right]$, Haroldo Lins e Silva, 1976, "Você frente a frente com o advogado de família", p. 76-77).

A disposição das classes no plano cartesiano possibilita-nos a leitura do conjunto das classes segundo dois possíveis eixos de referência (Figura 2 - Análise Fatorial de Correspondência). O primeiro é composto pela diferenciação entre os discursos técnicos (Classes 3 e 5) e aquele que trata, tentando descrever e explicar, das 
relações sociais (Classes 1,2 e 4$)^{4}$. 0 segundo eixo de referência baseia-se na pressuposta presença (Classes 1, 2, 3 e 4) ou ausência do pai (Classe 5).

Passaremos, agora, à discussão desse conjunto de resultados.

\section{Discussão}

Apesar das referências explícitas a "pai" nos textos analisados (critério para coleta), o termo não aparece em foco a não ser na classe "pai jurídico". Essa classe, como vimos, agrega os termos jurídicos relativos a pensão alimentícia, guarda dos filhos, reconhecimento de paternidade, separação e divisão de bens. Portanto, trata-se de uma referência clara a situações nas quais o casal não está mais junto ou encontra-se em processo de separação, o que permite que afirmemos que esse conjunto de referências agrupadas sob o nome "pai jurídico" é caracterizado não pela presença do pai, mas por sua ausência.

Referências aos pais (mãe e pai) são características de uma classe em que dar limites (limit+) às crianças e adolescentes aparece como central, o que reitera a relação tradicional paternidade/autoridade. Tal relação, já conhecida (Sarti, 1996), diferencia-se do cuidado materno, relativo ao contexto doméstico mais cotidiano, da autoridade exercida pelos pais, reconhecida como legitimada referência moral e última palavra nas questões relacionadas ao mundo público.

Outro vocábulo que remete ao grupo mais próximo da criança/adolescente é "família". Esse vocábulo, característico da classe "Terapia", e que também poderia contemplar a referência a pai, surge, no corpus analisado, como associado a problema, sobretudo de ordem psicológica. Temos aqui o discurso dos profissionais da área psi (principalmente psicólogos e psiquiatras) descrevendo/diagnosticando possíveis distúrbios cotidianos e, ao mesmo, propondo-se como solução para esses mesmos distúrbios.

Na classe "as doenças dos bebês", encontramos um conjunto de elementos relacionados tanto à profilaxia e ao tratamento quanto à etiologia de distúrbios nos fetos e nos bebês. Essa classe indica que a revista, seguindo o progressivo aumento de recursos técnicos no campo da medicina, investiu, mais acentuadamente a partir do período 1979-1983, na veiculação de informações relativas a patologias dos fetos e bebês. Nesse sentido, ainda que admitamos que os itens analisados pretendam fornecer informações sobre a saúde do corpo, eles o fazem considerando a saúde como a ausência de doenças (Herzlich, 2005). Portanto, o que encontramos nessa classe foram informações/prescrições para se evitar doenças, ou seja, as referências reiteram os cuidados necessários para evitar essas doenças e a responsabilização dos cuidadores caso esse cuidado não seja efetivo.

Por último, a classe "Nós, as crianças e nossas histórias" agrupa elementos que caracterizam um discurso sobretudo descritivo de atividades infantis. Encontramos reunidos nessa classe os elementos tradicionais da visão idílica da infância, tempo de liberdade, de movimento, de descoberta e de ingenuidade (Chombart de Lauwe, 1991). Aqui, a figura central é a criança e o pai aparece como participante eventual em suas brincadeiras.

Considerando-se que as classes identificadas podem ser tomadas como conjuntos de referências na composição da representação de paternidade nas páginas da Pais \& Filhos, há alguns pontos de articulação dos significados das classes que gostaríamos de apontar.

Os três discursos técnicos veiculados de forma explícita na revista (Direito, Medicina e Psicologia/ Psiquiatria) compõem o quadro mais geral de referências para a descrição/prescrição do que é ser um bom pai. Tendo como fundamento a percepção compartilhada de que tais discursos são cientificamente ou juridicamente embasados, ou seja, espelham a realidade, as representações sociais de paternidade são construídas/veiculadas a partir de um critério não discutível de autoridade.

Nesse sentido, talvez possamos considerar a revista como uma espécie de "manual" que teria como objetivos ensinar pais e mães a desempenharem adequadamente suas funções. Deve-se considerar, além disso, o fato de que, para serem efetivas, as prescrições estão fortemente vinculadas à descrição de problemas relacionados ao não cumprimento dessas mesmas

\footnotetext{
4 Aqui é interessante observar que o vocabulário utilizado nas matérias que veiculam o discurso "psi” é bastante próximo daquele utilizado nas Classes "não técnicas"
} 


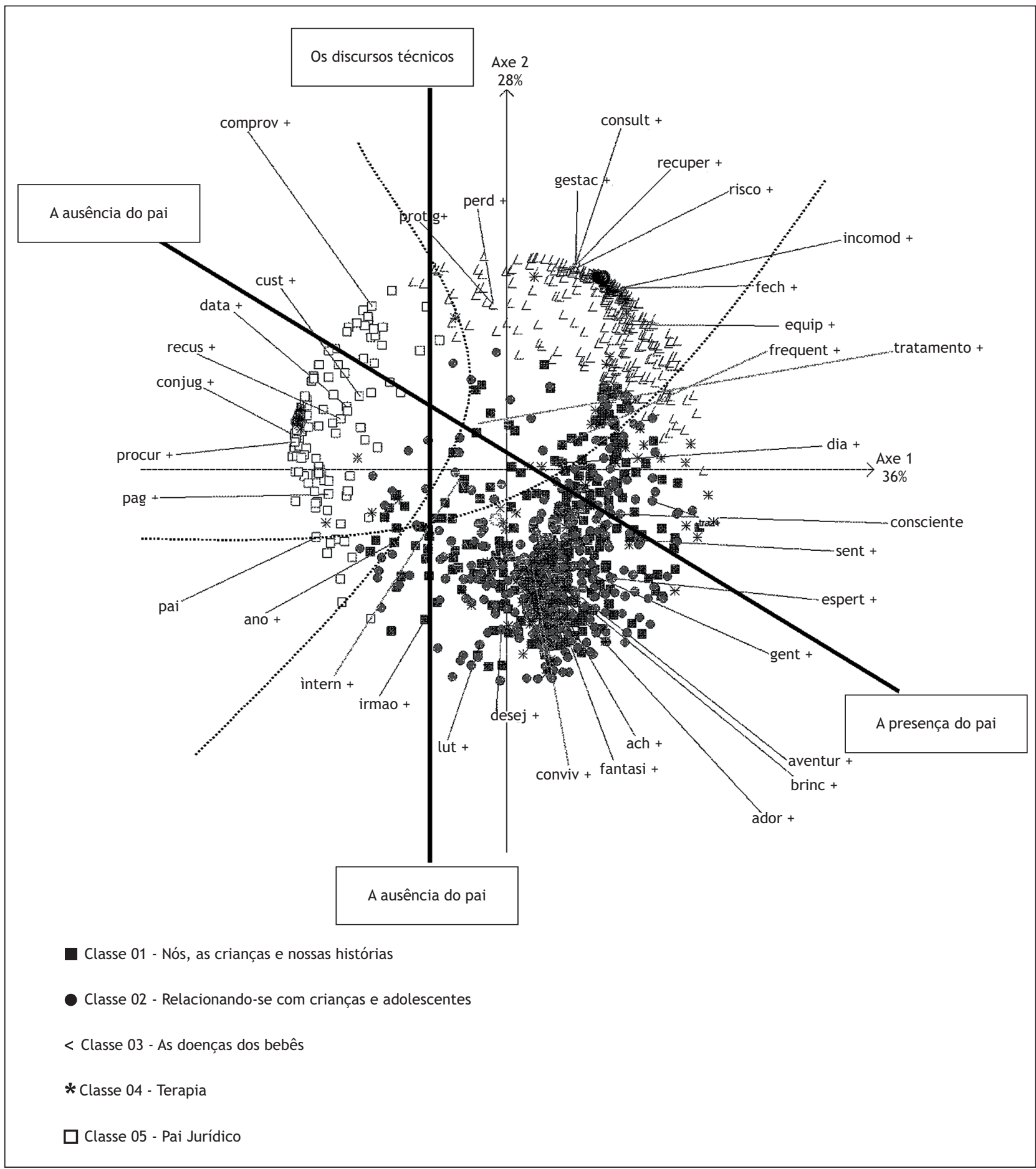

Figura 2 - Análise fatorial de correspondência Fonte: Dados da pesquisa.

prescrições. Temos assim, no corpus analisado, uma teoria social prática "cientificamente" embasada que permite descrever, prescrever e antecipar.

Também as duas classes que podem ser consideradas como características de discursos não técnicos ("Nós, as crianças e nossas histórias" e
"Relacionando-se com crianças e adolescentes") podem ser entendidas como servindo ao objetivo geral de ensinar sujeitos a serem pais e mães competentes. Por exemplo, no caso da classe "Nós, as crianças e nossas histórias" teríamos a infância, como já dissemos, idealizada, ou seja, livre dos 
problemas adultos ou, mais diretamente, livre de qualquer tipo de problemas. É interessante perceber que, nessa classe, a criança fala. Nas classes identificadas como de discurso técnico, fala-se sobre ela ("Terapia" e "As doenças dos bebês") ou por causa dela ("Pai jurídico").

Outro ponto de articulação que merece ser comentado é o entrelaçamento de objetos no corpus analisado (pai, mãe e criança/filho). Tal fato já era esperado. Primeiro porque o próprio critério de coleta dos itens analisados incluía o vocábulo "pais". Segundo, e também como validação dessa inclusão, a representação social de qualquer objeto só se dá por um processo de ancoragem que exige o seu entrelaçamento com outras representações (Moliner, 2001). Assim, a própria construção do significado da palavra "pai" exige, no mínimo, a construção dos significados de mãe e criança/filho.

Como conclusão, podemos afirmar que, no corpus analisado, a representação social de paternidade é composta por elementos que concedem ao pai o lugar de coadjuvante ou, mais recorrentemente, o identificam como uma referência associada a problemas ou a uma eventual possibilidade de solução para os mesmos. Nesse sentido, é preciso admitir que, nas páginas de Pais \& Filhos, a despeito do que afirma seu editorial, o "novo pai" ainda não encontrou seu lugar.

\section{Referências}

Assunção, C. Q. S. (2010). Belos, sadios e normais: As representações sociais dos corpos infantis modernos na Revista Pais\&Filhos (1968-1977). Dissertação de Mestrado não publicada, Programa de Pós-Graduação em Educação, Universidade Federal de Minas Gerais, Belo Horizonte.

Borlot, A. M. M., \& Trindade, Z. A. (2004). As tecnologias de reprodução assistida e as representações sociais de filho biológico. Estudos de Psicologia, 9(1), 63-70.

Buitoni, D. S. (2009). Mulher de papel: A representação da mulher pela imprensa feminina brasileira. (2. ed.). São Paulo: Summus.

Carvalho, J. B. L., \& Brito, R. S. (2008). Atitude do pai diante do nascimento. RENE, 9(4), 82-90.

Chechi, P., \& Hillesheim, B. (2008). Paternidade e mídia: Representações sobre o pai na contemporaneidade. Barbarói, 28, 89-108.
Chombart de Lauwe, M. J. (1991). Um outro mundo: $A$ infância. (N. Kon, Trad.). São Paulo: Perspectiva; Edusp. (Originalmente publicado em 1971).

Costa, N. R. A., \& Rossetti-Ferreira, M. C. (2007). Tornar-se pai e mãe em um processo de adoção tardia. Psicologia: Reflexão e Crítica, 20(3), 425-434.

Dias, A. B., \& Aquino, E. M. L. (2006). Maternidade e paternidade na adolescência: Algumas constatações em três cidades do Brasil. Cadernos de Saúde Pública, 22, 1447-1458.

Fonseca, J. L. C. L. (1998). Paternidade adolescente: Da investigação à intervenção. In M. Arilha, S. G. U. Ridenti \& B. Medrado (Org.). Homens e masculinidades: Outras palavras. (pp. 185-214). São Paulo: ECO/ Ed. 34

Ghirardi, M. L. A. M. (2009). A devolução de crianças adotadas: Ruptura do laço familiar. Pediatria Moderna, 45(2), 66-70

Hennigen, I., \& Guareschi, N. M. F. (2008). Os lugares de pais e de mães na mídia contemporânea: questões de gênero. Revista Interamericana de Psicologia, 42(1), 81-90.

Hennigen, I. (2010). Especialistas advertem: o pai é importante para o desenvolvimento infantil. Fractal: Revista de Psicologia, 22(1), 169-184.

Herzlich, C. (2005). Santé et maladie; analyse d'une représentation sociale. (6. ed.). Paris: Ed. de l'EHESS.

Hoga, L. A. K., \& Reberte, L. M. (2009). Vivencias de la paternidad en la adolescencia en una comunidad brasileña de baja renta. Revista da Escola de Enfermagem da USP, 43(1), 110-116.

Jodelet, D. (2005). Loucuras e representações sociais. (L. Magalhães, Trad.). Petrópolis: Ed. Vozes. (Originalmente publicado em 1989).

Jovchelovitch, S. (2007). Os contextos do saber: Representações, comunidades e cultura. (P. Guareschi, Trad.). Petrópolis: Vozes

Kalampalikis, N. (2003). L’apport de la méthode Alceste dans l'analyse dês représentations sociales. In J. C. Abric (Org.), Méthodes d'étude des représentations sociales (pp. 147-163). Paris: Érès.

Krob, A. D., Piccinini, C. A., \& Silva, M. R. (2009). A transição para a paternidade: Da gestação ao segundo mês de vida do bebê. Psicologia USP, 20(2), 269-291. 
Martins, A. L. (2008). Revistas em revista: Imprensa e Práticas Culturais em Tempos de República, São Paulo (1890-1922). São Paulo: Edusp.

Moliner, P. (2001). Une approche chronologique des représentations sociales. In P. Moliner (Dir.). La dynamique des représentations sociales (pp. 245-268). Grenoble: PUG.

Moscovici, S. (2004). Representações sociais: investigações em psicologia social. (P. A. Guareschi, Trad). Petrópolis: Vozes.

Nascimento, A. R. A., \& Menandro, P. R. M. (2006). Análise lexical e análise de conteúdo: uma proposta de utilização conjugada. Estudos e pesquisas em Psicologia, 6(2), 72-88.

Piccinini,C.A.,Levandowski,D.C.,Gomes,A.G.,Lindenmeyer, D., \& Lopes, R. S. (2009). Expectativas e sentimentos de pais em relação ao bebê durante a gestação. Estudos de Psicologia, 26(3), 373-382.

Pontes, C. M., Alexandrino, A. C., \& Osorio, M. M. (2009). 0 envolvimento paterno no processo da amamentação: Propostas de incentivo. Revista Brasileira de Saúde Materno-Infantil 9(4), 399-408.

Reinert, M. (1998). Alceste. Version 4.0 - Windows. Toulouse: Societé IMAGE. Manual.

Reinert, M. (2001). Alceste, une méthode statistique et sémiotique d'analyse de discours; Application aux «Rêveries du promeneur solitaire». La revue française de psychiatrie et de psychologie médicale, 5(39), 32-36.
Rodrigues, M. M. P. (2000). «Quem tem mãe tem tudo»: os pais e o desenvolvimento de crianças e jovens. In $\mathrm{H}$. A. Novo \& M. C. S. Menandro (Org.). Olhares Diversos: Estudando o desenvolvimento humano (pp. 143-156). Vitória: PPGP/Proin-Capes.

Santos, C. A. (2005). 0 discurso dos experts na constituição das identidades infantis e de gênero na mídia impressa brasileira. Pro-Posições, 16(3), 213-228.

Sarti, C. A. (1996). A família como espelho: Um estudo sobre a moral dos pobres. Campinas: Autores Associados.

Schwengber, M. S. V., \& Meyer, D. (2007). Educar corpos femininos como corpos grávidos um olhar de gênero sobre a Pais \& Filhos. Gênero, 7, 65-77.

Silva, M. R., \& Piccinini, C. A. (2007). Sentimentos sobre a paternidade e o envolvimento paterno: um estudo qualitativo. Estudos de Psicologia, 24(4), 561-573.

Sutter, C., \& Bucher-Maluschke, J. S. N. F. (2008). Pais que cuidam dos filhos: A vivência masculina na paternidade participativa. Psico 39(1),74-82.

Trindade, Z. A. (1998). Concepções de maternidade e paternidade: o convívio atual com fantasmas do século XVIII. In L. Souza, M. F. Q. Freitas \& M. M. P. Rodrigues (Org.). Psicologia: Reflexões (Im)pertinentes (pp. 129 155). São Paulo: Casa do Psicólogo.

Vidal, J., Rateau, P., \& Moliner, P. (2006). Les representations en psychologie sociale. In N. Blanc (Dir). Le concept de représentation em psychologie (pp. 11-42). Paris: In Press Éditions. 